\title{
Basaloid (Undifferentiated) Penile Intraepithelial Neoplasia
}

National Cancer Institute

\section{Source}

National Cancer Institute. Basaloid (Undifferentiated) Penile Intraepithelial Neoplasia. NCI

Thesaurus. Code C162542.

Intraepithelial neoplasia of the penis characterized by full-thickness replacement of the squamous epithelium by immature, small, monotonous, basophilic cells. The cells have round to oval nuclei, inconspicuous nucleoli, and scant cytoplasm. Apoptosis and mitotic figures are prominent. (WHO 2016) 